\title{
Acquired fluoroquinolone resistance genes in corneal isolates of Pseudomonas aeruginosa
}

Mahjabeen Khan1, Stephen Summers2, Scott A Rice2,3,4, Fiona Stapleton1, Mark D P Willcox1, and Dinesh Subedi1,5*

1School of Optometry and Vision Science, University of New South Wales Sydney, Australia 2The Singapore Centre for Environment Life Sciences Engineering (SCELSE), Singapore 3The School of Biological Sciences, Nanyang Technological University, Singapore 4The ithree Institute, The University of Technology Sydney, Sydney, New South Wales, Australia

5School of Biological Sciences, Monash University, Clayton, Victoria, Australia

Key words: Antimicrobial resistance, Fluroquinolones, Pseudomonas aeruginosa, eye, corneal ulcer, microbial keratitis

* Corresponding Author: dinesh.subedi@monash.edu 


\begin{abstract}
Fluroquinolones are widely used as an empirical therapy for pseudomonal ocular infections. Based on increasing reports on acquired fluroquinolone resistance genes in clinical isolates of Pseudomonas aeruginosa, we investigated 33 strains of $P$. aeruginosa isolated from the cornea of microbial keratitis patients in India and Australia between 1992 and 2018 to understand the prevalence of acquired fluroquinolone resistance genes in ocular isolates and to assess whether the possession of those genes was associated with fluoroquinolone susceptibility. We obtained the whole genome sequence of 33 isolates using Illumina MiSeq platform and investigated the prevalence of two fluoroquinolone resistance genes crpP and $q n r V C 1$. To examine the associated mobile genetic elements of qnrVCl positive strains, we obtained long read sequences using Oxford Nanopore MinION and performed hybrid assembly to combine long reads with Illumina short sequence reads. We further assessed mutations in QRDRs and antibiotic susceptibilities to ciprofloxacin, levofloxacin and moxifloxacin to examine the association between resistance genes and phenotype. Twenty strains possessed $\operatorname{crp} P$ in genetic islands characterised by possession of integrative conjugative elements. The qnrVCl gene was carried by four isolates on class I integrons and Tn 3 transposons along with aminoglycoside and beta-lactam resistance genes. We did not observe any evidence of plasmids carrying fluroquinolone resistance genes. Resistance to fluroquinolones was observed in those strains which possessed crpP, qnrVC1 and that had QRDRs mutations. The presence of $c r p P$ was not a sole cause of fluroquinolone resistance.
\end{abstract}

\title{
Introduction
}

Pseudomonas aeruginosa is a highly adaptable opportunistic pathogen which is ubiquitously present in the environment. This bacterium is naturally resistant to many antimicrobials and can acquire antibiotic resistance through mutations in chromosomal genes and lateral gene transfer $[1,2]$. $P$. aeruginosa is associated with different types of human infections and because of emerging multidrug-resistant strains, these infections are major global public health concerns [3].

Fluoroquinolones are broad spectrum and widely prescribed antibiotics to treat pseudomonal infections including ocular infections [4-6]. Fluoroquinolone resistance in various clinical isolates is on the rise [7]. For example, a single centre study has shown that the prevalence of fluoroquinolone resistance $P$. aeruginosa increased from $15 \%$ to $41 \%$ in ten years [8]. This increase in fluoroquinolone resistance has been linked to the excessive use of the antibiotics [9]. The rate of isolation of fluoroquinolone resistant strains also depends on the type of infections; nosocomial isolates are more resistant than isolates from non-nosocomial sources [10]. In general, fluoroquinolone resistance is relatively low in ocular isolates of $P$. aeruginosa compared to other infections [11]. However, higher resistance rates have been reported in ocular isolates in certain regions of the world and like other systemic infections this rate has been increasing over time [12]. This has raised the concerned that the horizontal transfer of fluoroquinolone resistance genes can be associated with spread of fluoroquinolone resistance in ocular isolates.

Mutations that alter target sites (DNA gyrase [ $g y r A / g y r B]$ and topoisomerase IV [parC/parE]) and increased membrane permeability are common mechanisms of fluoroquinolone resistance in $P$. aeruginosa [1, 13-15]. In other Gram-negative bacteria, fluoroquinolone resistance genes such as $q n r$ have been shown to be carried on plasmids [16, 17]. The gene encodes a pentapeptide repeat protein which protects DNA gyrase and topoisomerase from the action of fluroquinolones [18]. In contrast, carriage of qnr on plasmid is very rare in $P$. aeruginosa [19]. Despite this low carriage, recent studies have identified fluoroquinolone resistance genes in certain mobile genetic elements. CrpP and qnrVC can be carried on the $P$. aeruginosa mega plasmids pUM505 and pBM413, respectively [20, 21]. In addition, qnrVC was found to be associated with a class I integron, which also carried beta-lactamase genes [20, 22]. These studies were based on a single strain and the prevalence of acquired fluoroquinolone resistance genes in $P$. aeruginosa remains unclear. This led us to examine mobile fluoroquinolone resistance genes in $P$. aeruginosa. Given the concern of increasing fluoroquinolone resistance 
in ocular isolates, we have undertaken sequence analysis of 33 ocular isolates of $P$. aeruginosa, isolated from corneal ulcers in the last 25 years to assess whether the possession of fluoroquinolone resistance genes was associated with fluoroquinolone susceptibility and whether resistance genes carrying strains had any genetic commonalities.

\section{Materials and Methods}

\section{Pseudomonas aeruginosa strains}

Isolates in this study were collected from the cornea of microbial keratitis patients in India and Australia between 1992 and 2018. They comprise 20 isolates collected for this study and used for the antibiotic susceptibility testing and whole genome sequencing. Information on antibiotic susceptibility and the whole genome data of 13 isolates was obtained from our previous study [23] (Supplementary Table 1). All isolates were retrieved from the culture collection of School of Optometry and Vision Science, the University of New South Wales, Australia without identifiable patients' data.

Antibiotic susceptibility testing of Pseudomonas aeruginosa strains

Susceptibility of P. aeruginosa isolates to ciprofloxacin (Sigma-Aldrich, Inc., St. Louis Missouri, USA), levofloxacin (SigmaAldrich, Inc.,) and moxifloxacin (European Pharmacopoeia, Strasbourg, Cedex France) was investigated using the broth microdilution method following the protocol of Clinical and Laboratory Standard Institute [24] [25]. The MIC was taken as the lowest concentration of an antibiotic in which no noticeable growth (turbidity) was observed and the break point was established according to published standards [26]. Based on MICs, the isolates were categorised into four groups, susceptible ( $\leq$ resistance break point), resistant ( $>$ resistance break point $-32 \mu \mathrm{g} / \mathrm{mL}$ ), highly resistant $(>32-128 \mu \mathrm{g} / \mathrm{mL}$ ) and very highly resistant $(>128 \mu \mathrm{g} / \mathrm{mL})$ for the analysis.

\section{DNA extraction and Illumina sequencing}

Bacterial DNA was extracted from overnight cultures using a DNeasy Blood and Tissue Kit (Qiagen, Hilden, Germany) following the manufacturer's instructions. The extracted DNA was quantified and purity-checked using Nanodrop (NanoDrop Technologies, Wilmington, DE, USA), Qubit fluorometer (Life Technologies, Carlsbad, CA, USA), and 1\% agarose gel electrophoresis. The extracted DNA was dried for transport to the sequencing facility at Singapore Centre for Environmental Life Sciences Engineering, Singapore. DNA was sequenced on MiSeq (Illumina, San Diego, CA, USA) generating 300 bp paired end reads. The paired-end library was prepared using Nextera XT DNA library preparation kit (Illumina, San Diego, CA, USA). All the libraries were multiplexed on one MiSeq run.

\section{Bioinformatics analysis of short read sequences and construction of phylogenies}

The quality of raw reads was analysed using online tool FastQC v0.117 (https://www.bioinformatics.babraham.ac.uk/projects/fastqc). Adaptor sequences were removed using Trimmomatic v0.38 with quality and length filtering (SLIDINGWINDOW:4: 15 MINLEN:36) [27]. The reads were de-novo assembled using Spades v3.13.0 with the programs' default setting [28] followed by annotation using Prokka v1.12 [29]. To examine acquired resistance genes, the genomes were uploaded into online database ResFinder v3.1 of Centre for Genomic Epidemiology, DTU, Denmark [30]. The contigs carrying crpP and qnrVC1 genes were selected and analysed for mobile genetic elements using BLAST, Integron finder v1.5.1 [31] and IS finder [32]. The genome was visualised and manually modified using Geneious prime v2019.2 [33]. A figure of BLAST comparison was generated using EasyFig v2.2.2 [34]. To identify mutations in the QRDRs ( gyrA, gyrB, parC and parE), the genome sequences were analysed using Snippy v4.2 with program's default settings (https://github.com/tseemann/snippy). The genomes were also examined for the presence of type IV secretion factors (exoU and exoS) using BLAST search, and for the presence of the CRISPR cas system using the CRISPRcasFinder online tool [35]. Codon adaptation index (CAI) [36] was examined to understand the possible expression of different orthologues of $\operatorname{crpP}$ using CAIcal [37, 38]. 50s ribosomal protein L19 $(r p l S)$, which is a highly expressed chromosomal gene was included as the reference to show the difference in expression level between chromosomal gene and acquired genes.

Core genome single nucleotide polymorphisms (SNPs) were identified using Parsnp v from Harvest Suite [39] using settings to exclude SNPs identified in regions that had arisen by recombination. The core genome SNPs were used to construct a maximum likelihood phylogenetic tree. All genomes were examined for multi-locus sequence type (MLST) using the MLST database. Nucleotide sequences of all MLST locus were extracted and concatenated to use in Bayesian phylogenetic analyses using BEAST2 v2.4.7 with the following parameters: gamma site heterogeneity model, Hasegawa-Kishino-Yano (HKY) substitution model and relaxed-clock log-normal [40]. BEAST 2 output was summarized using TreeAnnotator with a 5\% burn in. The phylogenetic trees were visualised using iTol v4 [41].

\section{MinION sequencing and analysis}

Wizard Promega DNA extraction kits (Promega, Madison, WI) was used to extract DNA from overnight broth culture. DNA was quantified and transported as mentioned above. Long reads libraries were prepared using a rapid sequencing kit (RADSQK004, ONT, Oxford, UK) and subsequent sequencing was conducted using the MinIon flowcell (R9.4.1) for 48 hours. Long reads were basecalled using Guppy v3.3.0 and adapters removed using Porechop v0.2.4. Assembly of both long and short reads into a hybrid genome assembly was achieved with Unicycler v0.4.3 [42], opting for default parameters and using only short reads with merging pairs. Following assembly, all assemblies were assessed for quality using Quast v5.0.2. 


\section{Results}

\section{Population structure, phylogeny and fluoroquinolone resistance of $P$. aeruginosa strains}

Whole genomes were analysed from 33 corneal isolates of $P$. aeruginosa, 20 of which were sequenced as a part of this study and 13 genome that were published previously [23]. All strains were isolated between 1992 and 2018 in India (19 isolates) or Australia (14 isolates) (Supplementary Table 1). Draft genomes were mapped against the reference genome $P$. aeruginosa PAO1 and a total of 202,232 SNPs were observed among the 33 isolates, which were used to construct core genome phylogeny using Parsnp v1.2 [43]. Similar to previous reports $[23,36,44,45]$, the phylogenetic tree based on the core genome revealed two major clades (Fig 1). These clades followed a similar pattern as for other previously described strains of $P$. aeruginosa, where exo $U$ carrying strains clustered together in a single clade (Phylogroup 2) [23]. Our results showed that 18 (of 33) isolates carried exoU, of which 16 were clustered together in phylogroup 2, which contained predominantly Indian isolates. The detection rate of exoU was $68 \%$ in Indian isolates and $36 \%$ in Australian isolates.

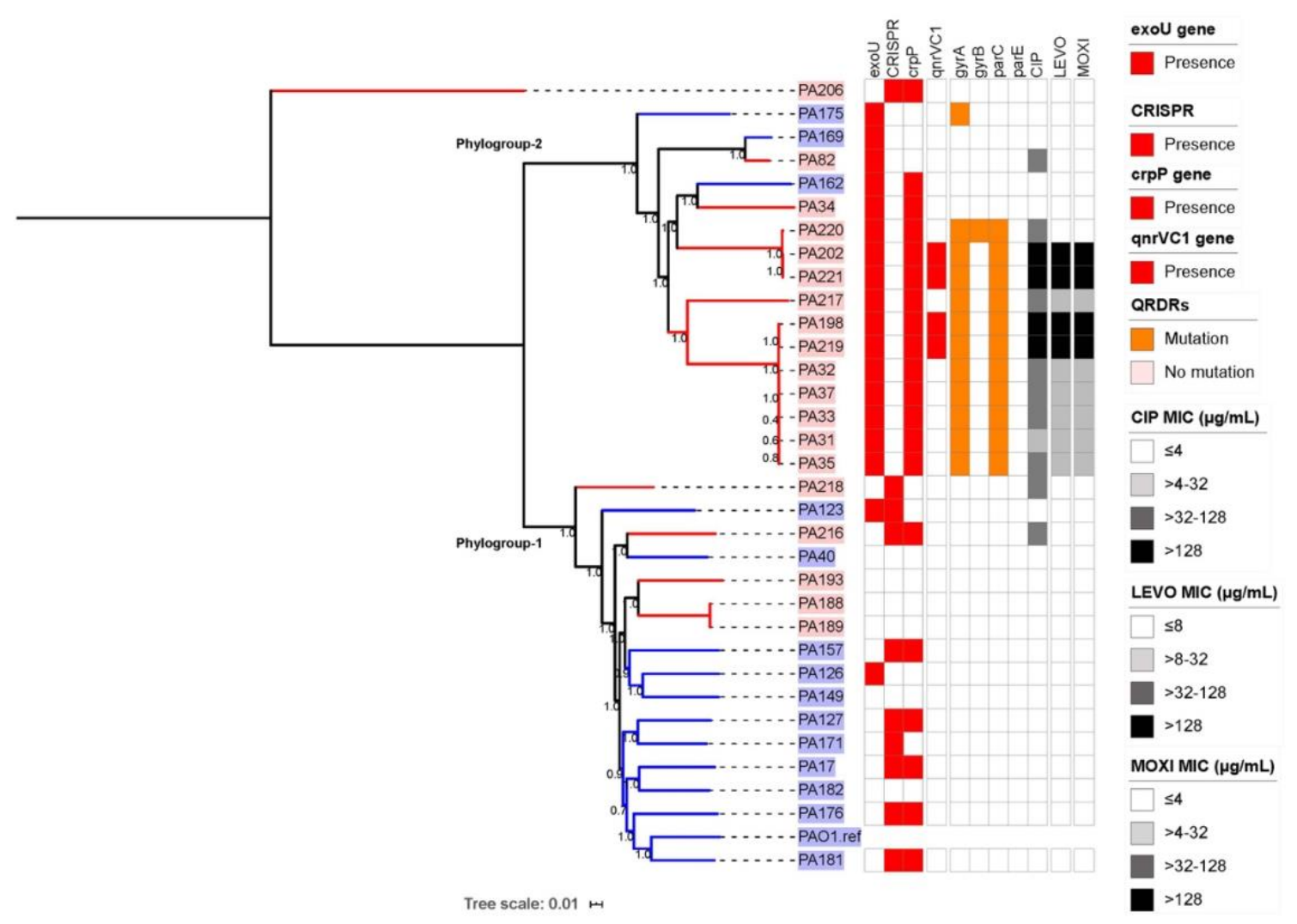

Figure 1. Maximum likelihood phylogenetic tree based on core genome SNPs analysis using Pseudomonas aeruginosa PAO1 as the reference, excluding SNPs identified in regions that had arisen by recombination, using the default parameters of Parsnp v1.2 [43]. Isolates from India are labelled red and Australian isolates are labelled blue. Numbers given at the nodes represent bootstrap values. The presence of crpP, exoU, qnrVC1, and CRISPR cas are represented by red squares. Orange squares represent the presence of mutations in the quinolone resistance determining regions (QRDRs) and fluoroquinolone (CIP = Ciprofloxacin; LEVO = Levofloxacin; and MOX = Moxifloxacin) susceptibilities are shown as a heat map with the ranges indicated in the figure. The figure was drawn using iTol v4 [41]. 
We further examined acquired fluoroquinolone resistance genes, mutations in quinolone resistance determining region (QRDRs), the presence of CRISPR genes and susceptibility to three different fluoroquinolones (Fig 1). None of the Australian isolates regardless of phylogenic grouping were resistant to fluoroquinolones. In contrast, $75 \%$ of isolates of phylogroup 2 were resistant to at least one fluoroquinolone. Of the 33 strains, $73.7 \%$ (14 out of 19) of Indian and 42.8\% (6 out of 14) of Australian isolates possessed crpP, which has been recently shown to be on a plasmid (pUM505) and associated with ciprofloxacin resistance [20]. However, eight (40\%) crpP carrying strains in the current study regardless of country of isolation were not resistant to the fluoroquinolones, including ciprofloxacin (Fig 1). Eleven out of 14 fluoroquinolone resistance strains had mutations in both gyrA and parC and all except one carried the exoU gene. In addition, four strains from the latter cohort of 11 strains carried another fluoroquinolone resistance gene, $q n r V C 1$, in combination with mutations in $g y r A$ and $\operatorname{par} C$, and this was associated with a very high MIC $(>128 \mu \mathrm{g} / \mathrm{mL})$ to all three fluoroquinolones (Fig 1).

Given that exoU, $\operatorname{crpP}$ and $q n r V C 1$ are components of the accessory genome which is mostly shaped by the CRISPR-Cas system, a bacterial defence system against foreign DNA [46], we searched isolates for CRISPR-Cas genes using the CRISPRCasFinder database [35] following software default parameters. Only one of the exoU, and none of the qnrVCl carrying strains, were positive for CRISPR-Cas genes. However, CRISPR-Cas was observed in seven crpP positive strains, which did not possess exoU and/or qnrVCl (Fig 1).

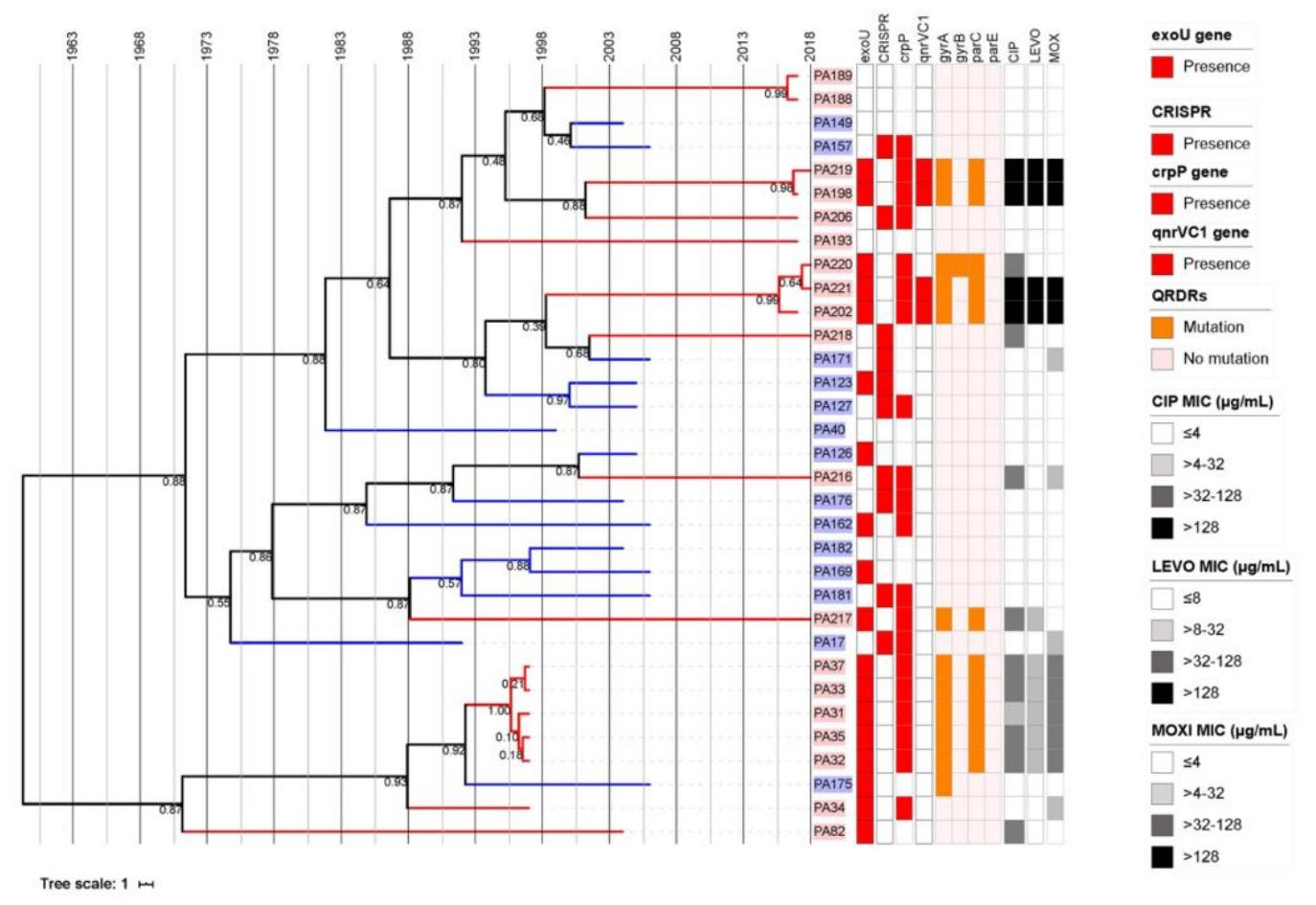

Figure 2. Consensus tree of 33 P. aeruginosa isolates, based on Bayesian evolutionary analysis by sampling trees (BEAST) of concatenated multi-locus sequence type (MLST) under strict clock analysis [40]. The tip of the tree was constrained by date of isolation. The time scale is shown in years at the top and each internal node is labelled with posterior probability limit. Isolates from India are labelled red and Australian isolates are labelled blue. The presence of genes crpP, exoU, qnrVC1, and CRISPRcas are represented by red squares. Orange square represents presence of mutations in quinolone resistance determining region (QRDRs), Fluoroquinolone (CIP = Ciprofloxacin; LEVO = Levofloxacin; and MOX $=$ Moxifloxacin) susceptibilities are shown as heat maps in the grey scale indicated in the figure. The figure was drawn using iTol v4 [41]. 


\section{Bayesian phylogenetic reconstruction}

To examine the evolutionary trends of isolates, a Bayesian analysis was performed based on MLST sequences. The evolutionary tree was constructed by BEAST, which uses a molecular clock model to estimate time-measured phylogenies [40]. The result suggested that the most recent common ancestor of isolates of this study appeared approximately 50 years ago and the branching of fluoroquinolone resistant strains (except PA82), which had mutations in QRDRs and/or had acquired resistance qnrVCl within each subclade, occurred between 1988 and 2000 (Fig 2). This coincided with the time when ciprofloxacin and ofloxacin were introduced as antibiotic treatments [47]. The analysis suggests that acquisition of $\operatorname{crpP}$ and exoU occurred at least 50 years ago.

\section{Prevalence of the crpP gene}

A recent study has shown that $\operatorname{crpP}$ encodes for a protein that is associated with increased resistance to ciprofloxacin [20]. In the current study, 63\% of isolates possessed this gene, however nine out of the $20 \mathrm{crpP}$ carrying strains were not resistant to ciprofloxacin (Fig 1). Single nucleotide polymorphisms in the $\operatorname{crpP}$ sequences from all strains were compared to the sequence of $c r p P$ in pUM505 using local BLASTn. The BLAST matrix (Table 1) showed that the nucleotide sequences of $\operatorname{crpP}$ genes varied between $100 \%$ and $93.43 \%$, indicating the possibility of differences in the activity of the encoded protein. Codon usage, presented as codon adaptation index [36] (Fig 3) was examined to understand the possible expression of different orthologues of crpP [38]. The 50s ribosomal protein L19 ( $r p l S$ ), which is a highly expressed chromosomal gene was included in this analysis to show the difference in expression between chromosomal and acquired genes. A CAI between 0.36 and 0.39 was observed in different orthologues of $\operatorname{crpP}$, which while low, corresponded to divergence of sequences. However, the sequence divergence was not associated with resistance to fluoroquinolones. For example, the nucleotide sequence of $\operatorname{crpP}$ of a resistant strain PA32 and a sensitive strain PA127 were $98.48 \%$ identical to that of pUM505.

This study also investigated the presence of the $\operatorname{crpP}$ homologues in NCBI databases using local BLAST with a cut off of $80 \%$ coverage and $90 \%$ sequence identity to examine the distribution of $\operatorname{crpP}$ gene in the bacterial database including plasmids as of 2019-06-15. The BLAST search against $P$. aeruginosa complete genome databases returned $52 \%$ matches and this rate of detection is broadly comparable to $\operatorname{crpP}$ prevalence observed in the current strains. No BLAST matches other than $P$. aeruginosa were observed with this search parameter. Within the $P$. aeruginosa plasmid database, two matches were observed against 45 complete plasmids using the parameters mentioned above. A CrpP-like protein, which has sequence identity of 10-46\% with $P$. aeruginosa crpP, has been observed in species of the Enterobacteriaceae [48]. This result suggested that crpP can be transferred between species or strains. 
Table 1: BLAST matrix showing nucleotide identity (in percentage) of $\operatorname{crpP}$ sequences of each isolate. Colour intensity corresponds to percentage identity.

\begin{tabular}{|c|c|c|c|c|c|c|c|c|c|c|c|c|c|c|c|c|c|c|c|c|c|}
\hline & pUM505* & PA31 & PA32 & PA33 & PA35 & PA37 & PA127 & PA162 & PA220 & PA17 & PA34 & PA157 & PA206 & PA217 & PA181 & PA216 & PA202 & PA219 & PA221 & PA176 & PA198 \\
\hline pUM505* & & 98.48 & 98.48 & 98.48 & 98.48 & 98.48 & 98.48 & 98.48 & 98.48 & 97.98 & 97.98 & 97.98 & 97.98 & 97.98 & 96.46 & 95.45 & 94.95 & 94.95 & 94.95 & 94.44 & 94.44 \\
\hline PA31 & 98.48 & & 100 & 100 & 100 & 100 & 100 & 98.99 & 100 & 99.49 & 98.48 & 98.48 & 98.48 & 98.48 & 97.98 & 95.96 & 95.45 & 95.45 & 95.45 & 94.95 & 94.95 \\
\hline PA32 & 98.48 & 100 & & 100 & 100 & 100 & 100 & 98.99 & 100 & 99.49 & 98.48 & 98.48 & 98.48 & 98.48 & 97.98 & 95.96 & 95.45 & 95.45 & 95.45 & 94.95 & 94.95 \\
\hline PA33 & 98.48 & 100 & 100 & & 100 & 100 & 100 & 98.99 & 100 & 99.49 & 98.48 & 98.48 & 98.48 & 98.48 & 97.98 & 95.96 & 95.45 & 95.45 & 95.45 & 94.95 & 94.95 \\
\hline PA35 & 98.48 & 100 & 100 & 100 & & 100 & 100 & 98.99 & 100 & 99.49 & 98.48 & 98.48 & 98.48 & 98.48 & 97.98 & 95.96 & 95.45 & 95.45 & 95.45 & 94.95 & 94.95 \\
\hline PA37 & 98.48 & 100 & 100 & 100 & 100 & & 100 & 98.99 & 100 & 99.49 & 98.48 & 98.48 & 98.48 & 98.48 & 97.98 & 95.96 & 95.45 & 95.45 & 95.45 & 94.95 & 94.95 \\
\hline PA127 & 98.48 & 100 & 100 & 100 & 100 & 100 & & 98.99 & 100 & 99.49 & 98.48 & 98.48 & 98.48 & 98.48 & 97.98 & 95.96 & 95.45 & 95.45 & 95.45 & 94.95 & 94.95 \\
\hline PA162 & 98.48 & 98.99 & 98.99 & 98.99 & 98.99 & 98.99 & 98.99 & & 98.99 & 98.48 & 98.48 & 99.49 & 99.49 & 99.49 & 97.47 & 94.95 & 94.44 & 94.44 & 94.44 & 94.95 & 94.95 \\
\hline PA220 & 98.48 & 100 & 100 & 100 & 100 & 100 & 100 & 98.99 & & 99.49 & 98.48 & 98.48 & 98.48 & 98.48 & 97.98 & 95.96 & 95.45 & 95.45 & 95.45 & 94.95 & 94.95 \\
\hline PA17 & 97.98 & 99.49 & 99.49 & 99.49 & 99.49 & 99.49 & 99.49 & 98.48 & 99.49 & & 98.99 & 97.98 & 97.98 & 97.98 & 97.47 & 96.46 & 95.96 & 95.96 & 95.96 & 94.44 & 94.44 \\
\hline PA34 & 97.98 & 98.48 & 98.48 & 98.48 & 98.48 & 98.48 & 98.48 & 98.48 & 98.48 & 98.99 & & 98.99 & 98.99 & 98.99 & 97.47 & 95.45 & 94.95 & 94.95 & 94.95 & 93.43 & 93.43 \\
\hline PA157 & 97.98 & 98.48 & 98.48 & 98.48 & 98.48 & 98.48 & 98.48 & 99.49 & 98.48 & 97.98 & 98.99 & & 100 & 100 & 97.98 & 94.44 & 93.94 & 93.94 & 93.94 & 94.44 & 94.44 \\
\hline PA206 & 97.98 & 98.48 & 98.48 & 98.48 & 98.48 & 98.48 & 98.48 & 99.49 & 98.48 & 97.98 & 98.99 & 100 & & 100 & 97.98 & 94.44 & 93.94 & 93.94 & 93.94 & 94.44 & 94.44 \\
\hline PA217 & 97.98 & 98.48 & 98.48 & 98.48 & 98.48 & 98.48 & 98.48 & 99.49 & 98.48 & 97.98 & 98.99 & 100 & 100 & & 97.98 & 94.44 & 93.94 & 93.94 & 93.94 & 94.44 & 94.44 \\
\hline PA181 & 96.46 & 97.98 & 97.98 & 97.98 & 97.98 & 97.98 & 97.98 & 97.47 & 97.98 & 97.47 & 97.47 & 97.98 & 97.98 & 97.98 & & 93.94 & 93.43 & 93.43 & 93.43 & 93.43 & 93.43 \\
\hline PA216 & 95.45 & 95.96 & 95.96 & 95.96 & 95.96 & 95.96 & 95.96 & 94.95 & 95.96 & 96.46 & 95.45 & 94.44 & 94.44 & 94.44 & 93.94 & & 99.49 & 99.49 & 99.49 & 93.94 & 93.94 \\
\hline PA202 & 94.95 & 95.45 & 95.45 & 95.45 & 95.45 & 95.45 & 95.45 & 94.44 & 95.45 & 95.96 & 94.95 & 93.94 & 93.94 & 93.94 & 93.43 & 99.49 & & 100 & 100 & 93.43 & 93.43 \\
\hline PA219 & 94.95 & 95.45 & 95.45 & 95.45 & 95.45 & 95.45 & 95.45 & 94.44 & 95.45 & 95.96 & 94.95 & 93.94 & 93.94 & 93.94 & 93.43 & 99.49 & 100 & & 100 & 93.43 & 93.43 \\
\hline PA221 & 94.95 & 95.45 & 95.45 & 95.45 & 95.45 & 95.45 & 95.45 & 94.44 & 95.45 & 95.96 & 94.95 & 93.94 & 93.94 & 93.94 & 93.43 & 99.49 & 100 & 100 & & 93.43 & 93.43 \\
\hline PA176 & 94.44 & 94.95 & 94.95 & 94.95 & 94.95 & 94.95 & 94.95 & 94.95 & 94.95 & 94.44 & 93.43 & 94.44 & 94.44 & 94.44 & 93.43 & 93.94 & 93.43 & 93.43 & 93.43 & & 100 \\
\hline PA198 & 94.44 & 94.95 & 94.95 & 94.95 & 94.95 & 94.95 & 94.95 & 94.95 & 94.95 & 94.44 & 93.43 & 94.44 & 94.44 & 94.44 & 93.43 & 93.94 & 93.43 & 93.43 & 93.43 & 100 & \\
\hline
\end{tabular}




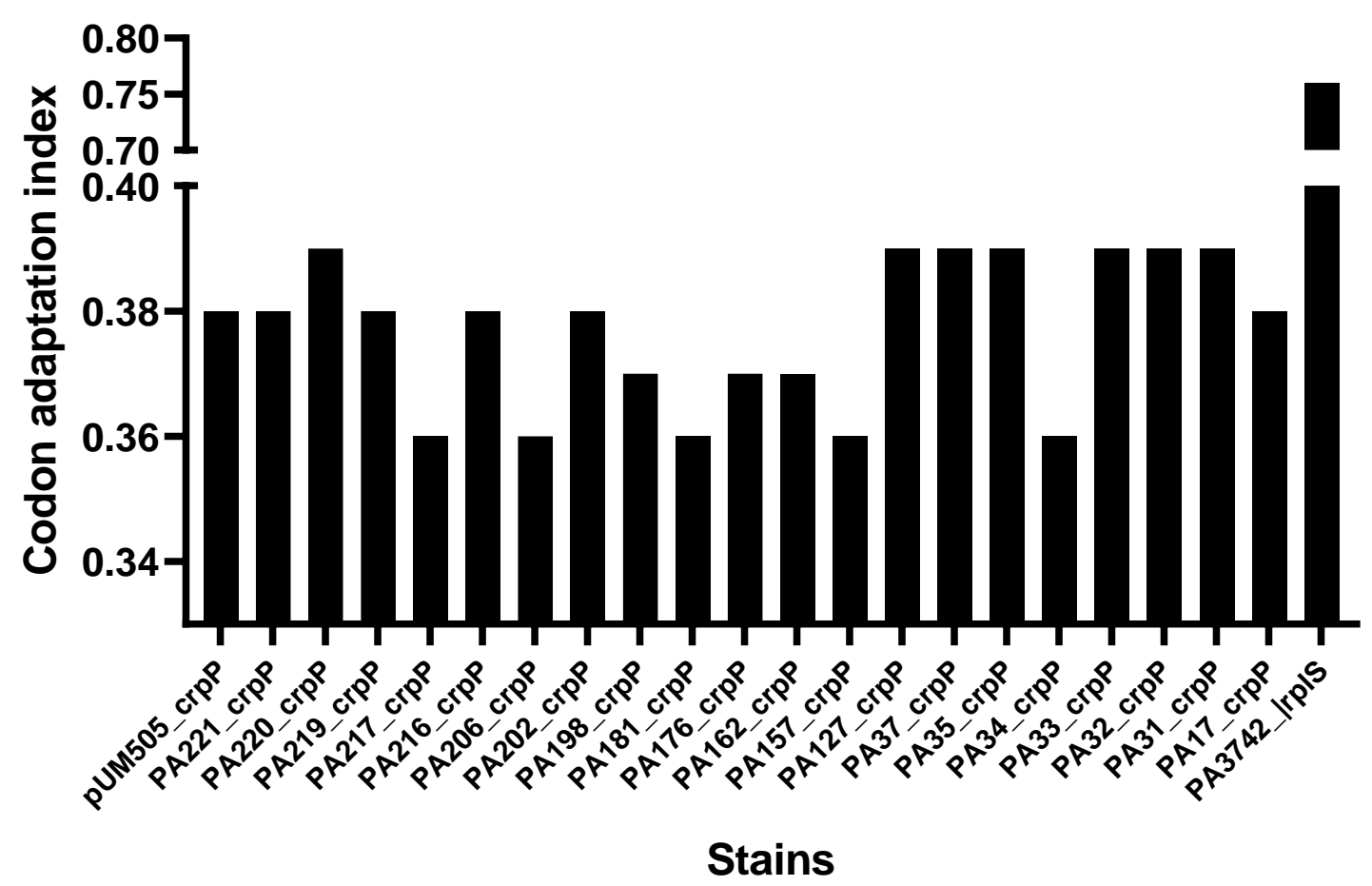

Figure 3. Codon adaptation index of $c r p P$ orthologues of $P$. aeruginosa strains. PA3742_rplS denotes 50s ribosomal protein L19 (rplS) of $P$. aeruginosa PAO1.

\section{crpP associated mobile genetic elements}

Although the $\operatorname{crpP}$ gene was first reported in plasmid pUM505 of a clinical strain of $P$. aeruginosa [20], BLAST analysis, as mentioned above, revealed this gene was mostly associated with the chromosome and its presence in plasmids was rare. The $\operatorname{crpP}$ containing contigs of each isolate were assessed to determine similarities between associated genomic islands. The $\operatorname{crpP}$ flanking region of pUM505 is homologous to the pathogenicity island PAPI1 of $P$. aeruginosa PA14 [49] and pKLC102 of $P$. aeruginosa C [50, 51], which is an integrative conjugative element and is associated with carriage of virulence genes. A PAPI-1like genomic island has also been reported in a complete genome of the ocular isolate PA34 [52]. Using PAPI-1 of PA34 as a reference, the contigs of each strain were compared and this showed that there were similarities between contigs. Those common regions were extracted and annotated manually using Geneious Prime v2019.1.3 [33]. After annotation, all of the extracted regions were compared using Easyfig [34]. The region that has been shared amongst all isolates is presented in Fig 4, where the colour code represents open reading frames. While the size of $\operatorname{crpP}$ carrying genomic islands differed between strains, the exact size of islands could not be ascertained because of the use of draft genomes for analysis. Nevertheless, three genes (integrative conjugative element, an unknown protein and single-strand binding protein) upstream and one gene (type I DNA topoisomerase) downstream of crpP were common in all isolates and this indicates that these genes may be involved in the transfer of $c r p P$ gene. A characteristic type IV pili synthesis operon was associated with $75 \%$ of the $\operatorname{crpP}$ positive strains. There was no association between size of $\operatorname{crpP}$ islands and fluoroquinolone resistance. 


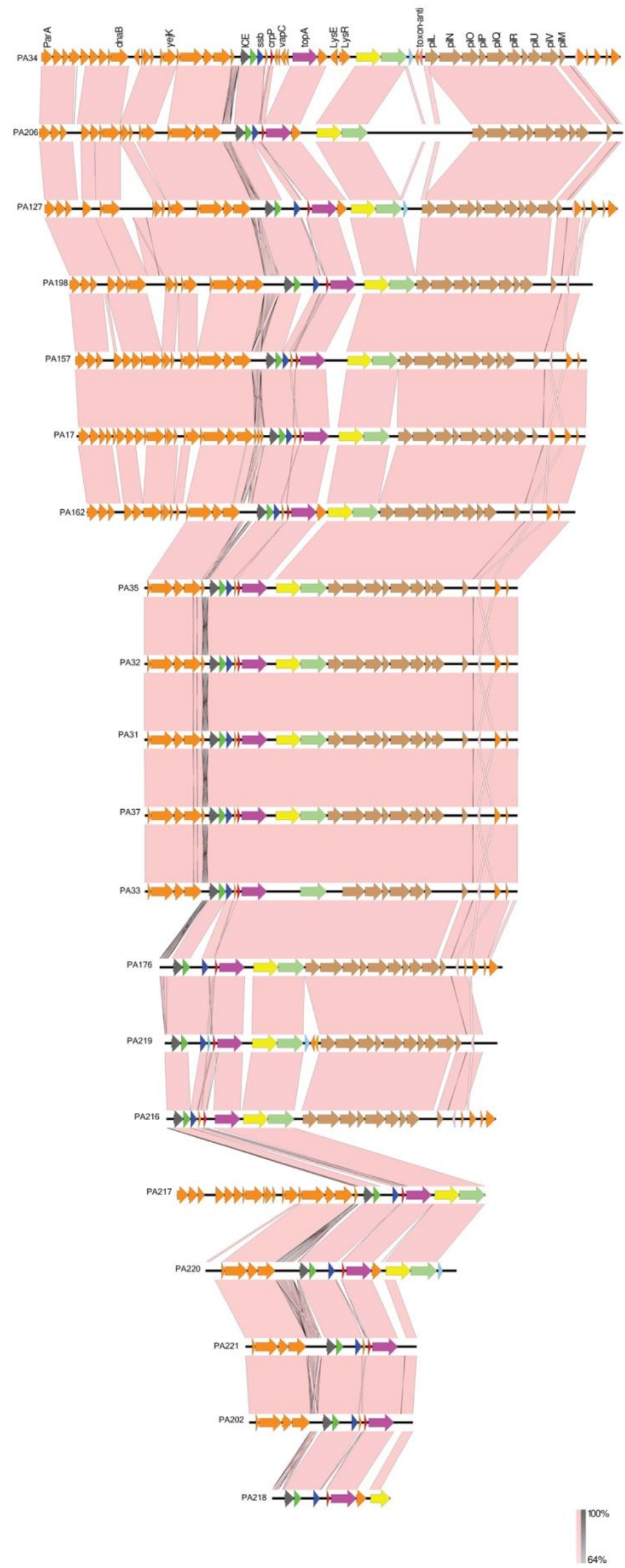


Figure 4. Comparison of crpP-associated genomic islands of $P$. aeruginosa strains. Protein-coding regions are represented by the orange arrows and common key features/associated genes among all strains are shown in various coloured arrows. The gradient pink and grey shading represent regions of nucleotide sequence identity (100\% to 64\%) in forward and reverse directions respectively, determined by BLASTn analysis. Figures are drawn to scale using Easyfig [34]. (parA= plasmid partition protein $A, d n a B=$ replicative DNA helicase, yejK= nucleoid-associated protein, $\mathrm{ICE}=$ integrating conjugative element protein, $\mathrm{ssb}=$ single-stranded $\mathrm{DNA}$-binding protein, crpP= ciprofloxacin resistance protein, vapC= tRNA(fMet)-specific endonuclease, topA = type I DNA topoisomerase, LysE= LysE family translocator, LysR= LysR family transcriptional regulator, toxin-anti= type II toxin-antitoxin system RelE/ParE family toxin, pilL-pilM= type IV pilus synthesis operon).

\section{Prevalence of quinolone resistance protein (qnr gene)}

The $q n r$ is commonly carried on plasmids, especially in the Enterobacteriaceae. A transferable variant of the $q n r$ gene, $q n r V C 1$ was first identified in a class I integron in Vibrio cholerae 01 [53]. Several qnrVC alleles have also been reported to be carried in various bacteria including $P$. aeruginosa $[18,54]$. For example, a recent study had reported that $2.3 \%$ of clinical strains of $P$. aeruginosa carried qnrVC [55]. In the current study, $12 \%$ (four out of 33) of isolates possessed $q n r V C 1$. All these four were isolated in 2017 and 2018. We further examined the prevalence of qnrVC1 homologues in complete chromosomes and plasmids of other bacterial species in NCBI database using BLAST search. We observed that qnrVCl-like proteins were present in several bacterial species. Upon limiting the BLAST criteria to $100 \%$ coverage and 98\% identity, the search returned with 19 matches from species of Pseudomonas, Vibrio and Aeromonas. (Supplementary Figure 1). This suggests that the qnrVC1 gene is prevalent in various bacterial families. Curiously, the qnrVCl gene was not identified in the plasmid database of NCBI. Furthermore, qnrVC1 had a G + C content of 37\%, which is considerably different from that of the $P$. aeruginosa genome $(66 \%)$. This evidence along with the presence of $q n r V C 1$ homologues in several bacterial species indicates that qnrVC1 is a horizontally acquired gene in $P$. aeruginosa, which is potentially acquired through inter-species or intergenera transfer.

\section{qnrVC1 associated mobile genetic elements}

We further examined the flanking nucleotide sequences of qnrVCl to understand the mobile genetic elements associated with transfer of the gene. Our initial analysis found that qnrVCl was present in small contigs (contig size $<5000 \mathrm{bp}$ ) and this limited our aim to examine mobile genetic elements. The four qnrVCl positive strains were then analysed using the long-read sequencing technique ONT minION (ONT, Oxford). With hybrid assembly of long and short sequencing reads, we archived long contigs ranging in size from $400 \mathrm{Kbp}$ to $2000 \mathrm{Kbp}$ (PA202 $\mathrm{N}_{50}=680,290 ;$ PA219 $\mathrm{N}_{50}=2,159,014 ;$ PA221 $\left.\mathrm{N}_{50}=2,110,541\right)$ in three isolates and a complete and closed genome of one strain PA198 (N50=7,188,952).

The qnrVC1 gene was present in two different types of mobile genetic elements. In strains PA198 and PA219, the gene was integrated into Tn3 transposons, which have 99\% identity with one another (Fig 5). In addition, the Tn 3 transposon carried other antibiotic resistance genes associated with aminoglycoside 3'-phosphotransferase and tetracycline resistance. BLAST comparison revealed recombination in various places within the transposon, most notably in the areas flanking the qnrVCl-VOC and tetR-tetA genes (Fig 5), which represents the site of integration of these genes. The role of VOC protein in antibiotic resistance is not well known. However, evidence suggests that proteins of VOC the family include beomycin and fosfomycin resistance proteins [56]. Integration of VOC with other antibiotic resistance 
genes leads us to hypothesise that VOC can be associated with antibiotic resistance. Further research is required to investigate its role in antibiotic resistance in P. aeruginosa.

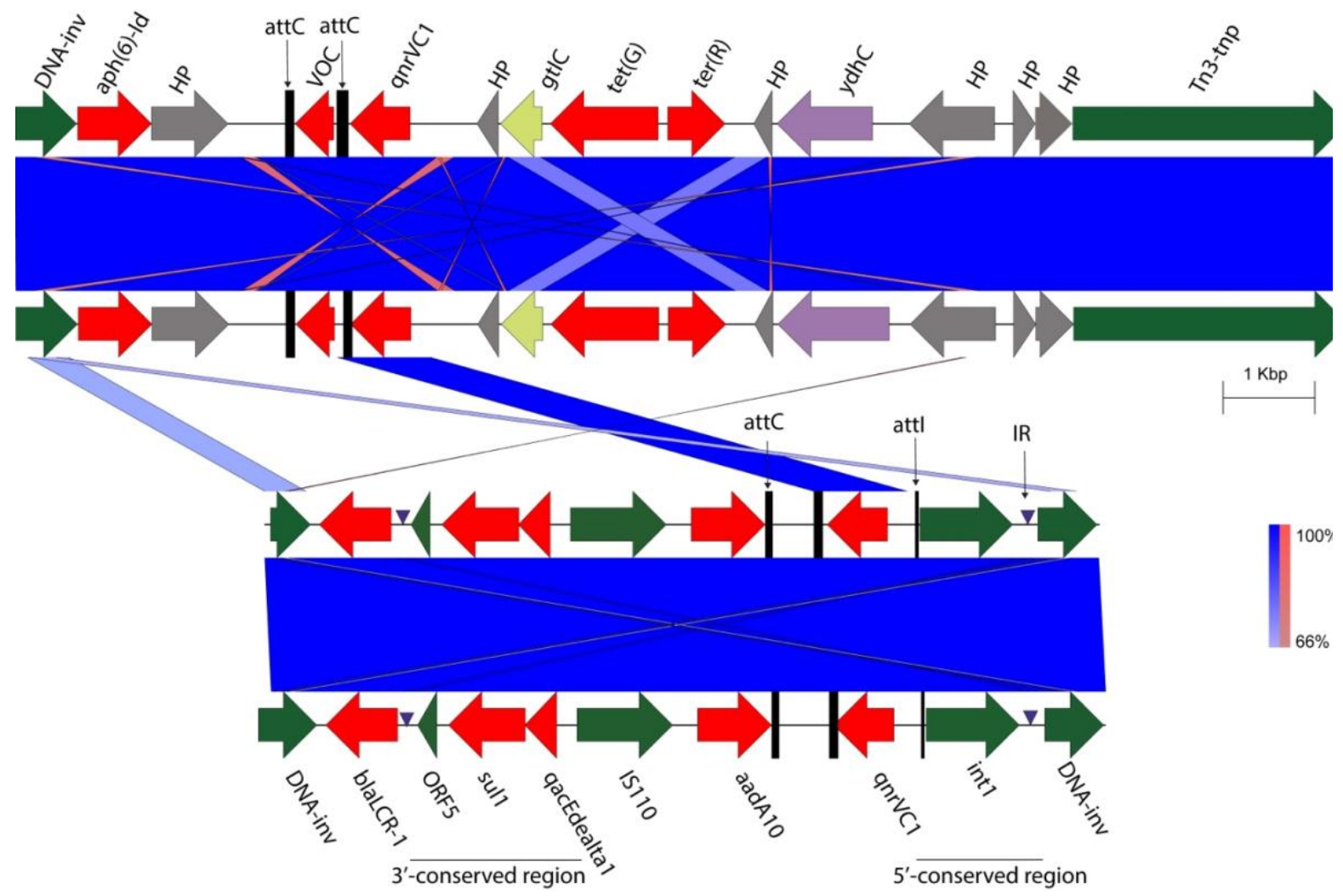

Figure 5. Comparison of qnrVCl-associated genomic islands of $P$. aeruginosa strains. Protein-coding regions are represented by the arrows and common key features/associated genes among all strains are shown in various coloured arrows. The gradient blue and red shading represent regions of nucleotide sequence identity (100\% to 65\%) in forward and reverse directions, respectively, determined by BLASTn analysis. The sequences are from strains top to bottom; PA198, PA219, PA202 and PA221. Figures are drawn to scale using Easyfig [34]. (Tn3-tnp $=$ Tn3-transposase HP= hypothetical protein, ydhC $=$ Inner membrane transport protein, tet $(\mathrm{R})$-tet $(\mathrm{g})=$ tetracycline resistance genes, $\mathrm{qnrVC} 1=$ quinolone resistance gene, $\mathrm{VOC}=\mathrm{VOC}$ family protein, $\mathrm{aph}(6)-\mathrm{Id}=$ aminoglycoside resistance protein, DNA-inv $=$ DNA invertase, aadA10 $=$ aminoglycoside resistance protein, IS110 = IS110 family transposase, qacEdealta $1=$ quaternary ammonium compound-resistance protein, sul1 $=$ Dihydropteroate synthase, blaLCR-1=betalactamase gene, attC = recombination sites of gene cassette, attI = integron recombination site, IR=invert repeat).

In the other two strains, PA202 and PA221, qnrVC1 was carried by identical class 1 integrons (Fig 5), along with two additional antibiotic resistance genes; the aminoglycoside gene aadA10 which was within the integron and the beta-lactam gene blaLCR-1 in the flanking region. Other studies have also shown that qnrVCl is a part of integrons that carry multiple resistance genes $[22,54]$. The class 1 integron observed here had a typical structure containing promoter sequences and an attachment site (attl) required for integration and transcription of gene cassettes [57]. The qnrVC1 gene in all four strains was associated with a perfectly matched gene recombination site (attC). The attC sequence of qnrVCl gene cassette had $100 \%$ identity with that of Vibrio parahaemolyticus (GenBank accession number EU436855), supporting the likelihood that the Vibrionaceae is a source of $q n r$ in P. aeruginosa [58]. 


\section{Discussion}

While fluoroquinolones are the preferred empirical therapy for corneal ulcers, which are often caused by $P$. aeruginosa, increasing resistance in this bacterium raises the concern about the efficacy of these antibiotics [4-11, 59, 60]. Acquired fluoroquinolone resistance genes are starting to be reported in clinical isolates of $P$. aeruginosa $[20-22,48]$. However, the rate of carriage of acquired fluoroquinolone resistance genes in ocular isolates has not been reported to date. This study examined the prevalence of acquired fluoroquinolone resistance genes, $\operatorname{crp} P$ and qnrVCl genes, which have recently been shown to be quinolone-associated acquired resistance genes in P. aeruginosa. We used whole genomes of 33 strains isolated from corneal ulcers in the last 25 years isolates from Australia and India. Fluoroquinolone resistance was common in Indian isolates and mutations in QRDRs were associated with this increased MIC to all three fluoroquinolones tested. Possession of the acquired gene qnrVCl substantially increased the MICs whereas $c r p P$ was not associated with increased fluoroquinolone resistance in those isolates that carried $\operatorname{crpP}$ but lacked QRDRs mutations or qnrVCl. Both quinolone resistance genes were integrated into the chromosome and their associated genomic islands were broadly common between strains.

Fluoroquinolone resistance in $P$. aeruginosa is usually associated with mutations in the genes mexR, $n f x B$, and mexT that lead to overexpression of efflux pumps and QRDRs of $g y r A$, gyrB, parC and parE that alter drug target sites [1, 13-15]. In addition, horizontally transferred fluoroquinolone resistance genes such as crpP and $q n r$-variants have been recently reported in clinical strains of $P$. aeruginosa [20-22, 55]. Our BLAST analysis against the NCBI database showed that more than half of strains in the $P$. aeruginosa complete genome database contained homologues of $c r p P$ and this corresponded to the detection frequency of $c r p P$ in the ocular strains reported in this manuscript. $C r p P$ carriage rate was higher in Indian isolates $(74 \%)$ compared to Australian isolates (43\%) and approximately half of the $\operatorname{crpP}$ carrying strains regardless of region of isolation were not resistant to any of the fluoroquinolones tested. Furthermore, fluoroquinolone resistant $\operatorname{crpP}+$ strains also had target site mutations $g y r A$ and $\operatorname{par} C$ and had acquired the quinolone resistance gene $q n r V C 1$. Therefore, the role of $\operatorname{crp} P$ alone on fluoroquinolone resistance could not be ascertained for these strains. Given that $\operatorname{crpP}$ is ciprofloxacin specific and associated with low-level resistance, its presence may not necessarily be responsible for MICs that exceeded the clinical breakpoint [20].

The $\operatorname{crpP}$ gene was associated with similar genomic islands in all strains. These genomic islands were characterised by the possession of integrative conjugative elements and DNA replication factors. The crpP gene was originally reported in the plasmid pUM505 [51] but there are no other studies showing plasmid associated $\operatorname{crpP}$ in $P$. aeruginosa. Therefore, we performed the BLAST search against the NCBI plasmid database specific to $P$. aeruginosa and observed two matches (plasmids pKLC102 and pY89) out of 45 complete plasmids. Furthermore, the most recent ancestors of $\operatorname{crpP}$ positive strains appeared at least 50 years ago, which is earlier than the appearance of resistant subclades in the phylogeny. This result, together with finding of high divergence in $c r p P$ orthologues between strains and lower CAI compared to a highly expressed chromosomal gene $(r l p S)$ [61] suggests that acquisition of the $\operatorname{crp} P$ gene was a relatively old evolutionary event in $P$. aeruginosa. In addition, the presence of CRISPR-Cas genes in several crpP positive strains supports the latter hypothesis and further suggests that $\operatorname{crp} P$ was integrated into the chromosome in an early event.

The plasmid-mediated quinolone resistance $q n r$ gene was first reported in 1998 [16] and this corresponds with increased usage of fluoroquinolones in the 1980s [62]. Our analysis also 
revealed that resistant $P$. aeruginosa strains were phylogenetically separated from susceptible strains from the 1990s. The $q n r$ genes protect DNA-gyrase and topoisomerase IV to prevent quinolone actions and confer low-level fluoroquinolones resistance, often below the clinical breakpoint $[63,64]$. The qnrVCl gene is a mobile quinolone resistance gene that is associated with class I integrons [53]. QnrVC1 and another variant qnrVC6 have been reported from clinical P. aeruginosa strains isolated between 2007 and 2012 [21, 54]. However, in this study, the acquired fluoroquinolone resistance gene qnrVCl was observed in isolates sampled in 2017 and 2018, indicating that transferable fluoroquinolone resistance genes may be recently acquired or passed unnoticed in ocular isolates of $P$. aeruginosa. No strains contained qnrVC6. We also observed that qnrVCl was associated with a Tn3 transposon, which has not been previously reported in P. aeruginosa. Integration of several other antibiotic resistance genes in these mobile genetic elements suggests these elements may concentrate antibiotic resistance genes. QnrVC is reported predominantly in water bacteria including Aeromonas spp., and Acinetobacter spp [65]. In this study the recombination site (attC) of all four qnrVCl alleles had $100 \%$ identity with aquatic bacteria Vibrio parahaemolyticus. This corresponds with our previous study in ocular isolates of $P$. aeruginosa, where acquired resistance genes closely matched with that of environmental isolates $[52,66]$.

However, the current study showed that qnrVCl carrying strains also had QRDRs mutations and were highly resistant to all three fluoroquinolones compared to those lacking qnrVCl. This indicates that possession of $q n r V C 1$ potentially facilitates selection of strains with high-level fluoroquinolone resistance. Given that $q n r V C 1$ has been reported as being responsible for lowlevel fluoroquinolone resistance [18], the high MICs observed for these isolates is not clear but may indicate some synergistic activity between the QRDR mutations and qnrVC1.

Like in many other studies, fluoroquinolone resistant strains were also associated with possession of exoU, which is the predominate virulent genotype of $P$. aeruginosa in ocular infections [67-77]. Although the reason behind this predominance is not completely understood, the concurrent occurrence of transferable fluoroquinolone resistance genes and exoU may heighten the concern of selection of more virulent strains during antibiotic therapy.

In conclusion, mobile genetic elements play a key role in the rapid spread of antibiotic resistance genes. This study provides evidence for carrying of fluoroquinolone resistance genes $q n r V C l$ and $c r p P$ in ocular isolates of $P$. aeruginosa. The qnrVCl gene was mobilised by a class I integron and Tn3 transposon, and associated with other antibiotics resistance genes. The crpP gene may have evolved prior to other transferable fluoroquinolone resistance genes. Although possession of these genes has not been shown to be associated with high level of fluroquinolone resistance, $q n r V C l$ in strains with $g y r A$ and $\operatorname{parC}$ mutations could be associated with very high fluroquinolone resistance. Further studies on a larger number of fluoroquinolone resistance strains, including molecular analysis of combined effects of mutations in resistance, should be undertaken to provide further insights into the role of acquired fluoroquinolone resistance gene in clinically significant resistance in $P$. aeruginosa.

\section{Nucleotide accession}

The nucleotide sequences are available in the GenBank under the Bio project accession number PRJNA590804 and PRJNA431326.

\section{Acknowledgements}

The authors would like to acknowledge the Singapore Centre for Environmental Life Sciences Engineering (SCELSE), whose research is supported by the National Research Foundation Singapore, Ministry of Education, Nanyang Technological University and National University of Singapore, under its Research Centre of Excellence Programme. We are also thankful to 
UNSW high performance computing facility KATANA for providing us cluster time for data analysis.

\section{Conflicts of interest}

No conflict of interest is declared by all authors.

\section{References}

1. Livermore DM. Multiple mechanisms of antimicrobial resistance in Pseudomonas aeruginosa: our worst nightmare? Clinical infectious diseases : an official publication of the Infectious Diseases Society of America. 2002;34(5):634-40. doi: 10.1086/338782. PubMed PMID: 11823954.

2. Blair JM, Webber MA, Baylay AJ, Ogbolu DO, Piddock LJ. Molecular mechanisms of antibiotic resistance. Nature reviews Microbiology. 2015;13(1):42-51. Epub 2014/12/02. doi: 10.1038/nrmicro3380. PubMed PMID: 25435309.

3. WHO priority pathogens list for R\&D of new antibiotics [Internet]. 2017.

4. Linder JA, Huang ES, Steinman MA, Gonzales R, Stafford RS. Fluoroquinolone prescribing in the United States: 1995 to 2002. Am J Med. 2005;118(3):259-68. Epub 2005/03/05. doi: 10.1016/j.amjmed.2004.09.015. PubMed PMID: 15745724.

5. Blondeau JM. Fluoroquinolones: mechanism of action, classification, and development of resistance. Survey of ophthalmology. 2004;49 Suppl 2:S73-8. Epub 2004/03/19. doi: 10.1016/j.survophthal.2004.01.005. PubMed PMID: 15028482.

6. Smith A, Pennefather PM, Kaye SB, Hart CA. Fluoroquinolones: place in ocular therapy. Drugs. 2001;61(6):747-61. Epub 2001/06/12. PubMed PMID: 11398907.

7. Neuhauser MM, Weinstein RA, Rydman R, Danziger LH, Karam G, Quinn JP. Antibiotic resistance among gram-negative bacilli in US intensive care units: implications for fluoroquinolone use. Jama. 2003;289(7):885-8. Epub 2003/02/18. PubMed PMID: 12588273. 8. Gasink LB, Fishman NO, Weiner MG, Nachamkin I, Bilker WB, Lautenbach E. Fluoroquinolone-resistant Pseudomonas aeruginosa: assessment of risk factors and clinical impact. Am J Med. 2006;119(6):526.e19-25. Epub 2006/06/06. doi:

10.1016/j.amjmed.2005.11.029. PubMed PMID: 16750968.

9. Werner NL, Hecker MT, Sethi AK, Donskey CJ. Unnecessary use of fluoroquinolone antibiotics in hospitalized patients. BMC infectious diseases. 2011;11:187. Epub 2011/07/07. doi: 10.1186/1471-2334-11-187. PubMed PMID: 21729289; PubMed Central PMCID: PMCPMC3145580.

10. Yayan J, Ghebremedhin B, Rasche K. Antibiotic resistance of Pseudomonas aeruginosa in pneumonia at a single University hospital center in Germany over a 10-year period. PloS one. 2015;10(10):e0139836. doi: 10.1371/journal.pone.0139836. PubMed PMID: 26430738; PubMed Central PMCID: PMCPMC4592231.

11. Subedi D, Vijay AK, Willcox M. Overview of mechanisms of antibiotic resistance in Pseudomonas aeruginosa: an ocular perspective. Clinical \& experimental optometry. 2018;101(2):162-71. Epub 2017/10/19. doi: 10.1111/cxo.12621. PubMed PMID: 29044738. 12. Smitha S, Lalitha P, Prajna VN, Srinivasan M. Susceptibility trends of Pseudomonas species from corneal ulcers. Indian journal of medical microbiology. 2005;23(3):168-71. PubMed PMID: 16100422.

13. Higgins PG, Fluit AC, Milatovic D, Verhoef J, Schmitz FJ. Mutations in GyrA, ParC, MexR and NfxB in clinical isolates of Pseudomonas aeruginosa. International journal of antimicrobial agents. 2003;21(5):409-13. PubMed PMID: 12727072.

14. Nakano M, Deguchi T, Kawamura T, Yasuda M, Kimura M, Okano Y, et al. Mutations in the gyrA and parC genes in fluoroquinolone-resistant clinical isolates of 
Pseudomonas aeruginosa. Antimicrobial agents and chemotherapy. 1997;41(10):2289-91. Epub 1997/10/23. PubMed PMID: 9333065; PubMed Central PMCID: PMCPMC164110. 15. Hooper DC. Mechanisms of fluoroquinolone resistance. Drug resistance updates : reviews and commentaries in antimicrobial and anticancer chemotherapy. 1999;2(1):38-55. doi: 10.1054/drup.1998.0068. PubMed PMID: 11504468.

16. Martinez-Martinez L, Pascual A, Jacoby GA. Quinolone resistance from a transferable plasmid. Lancet. 1998;351(9105):797-9. doi: 10.1016/S0140-6736(97)07322-4. PubMed PMID: 9519952.

17. Jacoby GA. Mechanisms of resistance to quinolones. Clinical infectious diseases : an official publication of the Infectious Diseases Society of America. 2005;41 Suppl 2:S120-6. Epub 2005/06/09. doi: 10.1086/428052. PubMed PMID: 15942878.

18. Robicsek A, Jacoby GA, Hooper DC. The worldwide emergence of plasmid-mediated quinolone resistance. The Lancet Infectious diseases. 2006;6(10):629-40. Epub 2006/09/30. doi: 10.1016/S1473-3099(06)70599-0. PubMed PMID: 17008172.

19. Cayci YT, Coban AY, Gunaydin M. Investigation of plasmid-mediated quinolone resistance in Pseudomonas aeruginosa clinical isolates. Indian journal of medical microbiology. 2014;32(3):285-9. Epub 2014/07/11. doi: 10.4103/0255-0857.136567. PubMed PMID: 25008822.

20. Chávez-Jacobo VM, Hernández-Ramírez KC, Romo-Rodríguez P, Pérez-Gallardo RV, Campos-García J, Gutiérrez-Corona JF, et al. CrpP Is a novel ciprofloxacin-modifying enzyme encoded by the Pseudomonas aeruginosa pUM505 plasmid. Antimicrobial agents and chemotherapy. 2018;62(6):e02629-17. doi: 10.1128/AAC.02629-17.

21. Liu J, Yang L, Chen D, Peters BM, Li L, Li B, et al. Complete sequence of pBM413, a novel multidrug resistance megaplasmid carrying qnrVC6 and blaIMP-45 from

Pseudomonas aeruginosa. International journal of antimicrobial agents. 2018;51(1):145-50. Epub 2017/09/20. doi: 10.1016/j.ijantimicag.2017.09.008. PubMed PMID: 28923459.

22. Kocsis B, Toth A, Gulyas D, Ligeti B, Katona K, Rokusz L, et al. Acquired qnrVC1 and blaNDM-1 resistance markers in an international high-risk Pseudomonas aeruginosa ST773 clone. Journal of medical microbiology. 2019;68(3):336-8. Epub 2019/01/23. doi: 10.1099/jmm.0.000927. PubMed PMID: 30667355.

23. Subedi D, Vijay AK, Kohli GS, Rice SA, Willcox M. Comparative genomics of clinical strains of Pseudomonas aeruginosa strains isolated from different geographic sites. Scientific reports. 2018;8(1):15668. Epub 2018/10/26. doi: 10.1038/s41598-018-34020-7. PubMed PMID: 30353070; PubMed Central PMCID: PMCPMC6199293.

24. CLSI. Clinical and Laboratory Standards Institute(CLSI). Performance standards for antimicrobial susceptibility testing; twenty-second information supplement. CLSI document M100-S22 32 (2012). 2012.

25. Clinical and Laboratory Standards Institute (CLSI). Methods for dilution antimicrobial susceptibility tests for bacteria that grow aerobically; approved standardNinth Edition. CLSI. 2012;32(M07-A9).

26. Clinical and Laboratory Standards Institute (CLSI). Performance standards for antimicrobial susceptibility testing; twenty-second information supplement. CLSI document M100-S22. 2012;32(3).

27. Bolger AM, Lohse M, Usadel B. Trimmomatic: a flexible trimmer for Illumina sequence data. Bioinformatics (Oxford, England). 2014;30(15):2114-20.

28. Bankevich A, Nurk S, Antipov D, Gurevich AA, Dvorkin M, Kulikov AS, et al. SPAdes: a new genome assembly algorithm and its applications to single-cell sequencing. $\mathrm{J}$ Comput Biol. 2012;19(5):455-77. doi: 10.1089/cmb.2012.0021. PubMed PMID: 22506599; PubMed Central PMCID: PMCPMC3342519. 
29. Seemann T. Prokka: rapid prokaryotic genome annotation. Bioinformatics (Oxford, England). 2014;30(14):2068-9. doi: 10.1093/bioinformatics/btu153. PubMed PMID: 24642063.

30. Zankari E, Hasman H, Cosentino S, Vestergaard M, Rasmussen S, Lund O, et al. Identification of acquired antimicrobial resistance genes. Journal of Antimicrobial Chemotherapy. 2012;67(11):2640-4. doi: 10.1093/jac/dks261.

31. Cury J, Jove T, Touchon M, Neron B, Rocha EP. Identification and analysis of integrons and cassette arrays in bacterial genomes. Nucleic acids research. 2016;44(10):453950. doi: 10.1093/nar/gkw319. PubMed PMID: 27130947; PubMed Central PMCID: PMCPMC4889954.

32. Siguier P, Perochon J, Lestrade L, Mahillon J, Chandler M. ISfinder: the reference centre for bacterial insertion sequences. Nucleic acids research. 2006;34(Database issue):D32-6. doi: 10.1093/nar/gkj014. PubMed PMID: 16381877; PubMed Central PMCID: PMCPMC1347377.

33. Kearse M, Moir R, Wilson A, Stones-Havas S, Cheung M, Sturrock S, et al. Geneious Basic: an integrated and extendable desktop software platform for the organization and analysis of sequence data. Bioinformatics (Oxford, England). 2012;28(12):1647-9. Epub 2012/05/01. doi: 10.1093/bioinformatics/bts 199. PubMed PMID: 22543367; PubMed Central PMCID: PMCPMC3371832.

34. Sullivan MJ, Petty NK, Beatson SA. Easyfig: a genome comparison visualizer. Bioinformatics (Oxford, England). 2011;27(7):1009-10. Epub 2011/02/01. doi: 10.1093/bioinformatics/btr039. PubMed PMID: 21278367; PubMed Central PMCID: PMCPMC3065679.

35. Couvin D, Bernheim A, Toffano-Nioche C, Touchon M, Michalik J, Néron B, et al. CRISPRCasFinder, an update of CRISRFinder, includes a portable version, enhanced performance and integrates search for Cas proteins. Nucleic acids research. 2018;46(W1):W246-W51. doi: 10.1093/nar/gky425.

36. Stewart L, Ford A, Sangal V, Jeukens J, Boyle B, Kukavica-Ibrulj I, et al. Draft genomes of 12 host-adapted and environmental isolates of Pseudomonas aeruginosa and their positions in the core genome phylogeny. Pathog Dis. 2014;71(1):20-5. doi: 10.1111/2049632X.12107. PubMed PMID: 24167005.

37. Puigbò P, Bravo IG, Garcia-Vallve S. CAIcal: a combined set of tools to assess codon usage adaptation. Biol Direct. 2008;3:38. Epub 2008/09/18. doi: 10.1186/1745-6150-3-38. PubMed PMID: 18796141; PubMed Central PMCID: PMCPMC2553769.

38. Sharp PM, Li WH. The codon Adaptation Index--a measure of directional synonymous codon usage bias, and its potential applications. Nucleic acids research. 1987;15(3):1281-95. Epub 1987/02/11. doi: 10.1093/nar/15.3.1281. PubMed PMID: 3547335; PubMed Central PMCID: PMCPMC340524.

39. Treangen TJ, Ondov BD, Koren S, Phillippy AM. The Harvest suite for rapid coregenome alignment and visualization of thousands of intraspecific microbial genomes. Genome biology. 2014;15(11):524.

40. Drummond AJ, Rambaut A. BEAST: Bayesian evolutionary analysis by sampling trees. BMC Evol Biol. 2007;7:214. Epub 2007/11/13. doi: 10.1186/1471-2148-7-214. PubMed PMID: 17996036; PubMed Central PMCID: PMCPMC2247476.

41. Letunic I, Bork P. Interactive Tree Of Life (iTOL) v4: recent updates and new developments. Nucleic acids research. 2019. doi: 10.1093/nar/gkz239. PubMed PMID: 30931475.

42. Wick RR, Judd LM, Gorrie CL, Holt KE. Unicycler: resolving bacterial genome assemblies from short and long sequencing reads. PLoS computational biology.

2017;13(6):e1005595. 
43. Treangen TJ, Ondov BD, Koren S, Phillippy AM. The Harvest suite for rapid coregenome alignment and visualization of thousands of intraspecific microbial genomes. Genome Biol. 2014;15(11):524. doi: 10.1186/PREACCEPT-2573980311437212. PubMed PMID: 25410596; PubMed Central PMCID: PMCPMC4262987.

44. Jeukens J, Kukavica-Ibrulj I, Emond-Rheault JG, Freschi L, Levesque RC. Comparative genomics of a drug-resistant Pseudomonas aeruginosa panel and the challenges of antimicrobial resistance prediction from genomes. FEMS Microbiol Lett. 2017;364(18). Epub 2017/09/20. doi: 10.1093/femsle/fnx161. PubMed PMID: 28922838.

45. Freschi L, Jeukens J, Kukavica-Ibrulj I, Boyle B, Dupont MJ, Laroche J, et al. Clinical utilization of genomics data produced by the international Pseudomonas aeruginosa consortium. Frontiers in microbiology. 2015;6:1036. Epub 2015/10/21. doi: 10.3389/fmicb.2015.01036. PubMed PMID: 26483767; PubMed Central PMCID: PMCPMC4586430.

46. van Belkum A, Soriaga LB, LaFave MC, Akella S, Veyrieras JB, Barbu EM, et al. Phylogenetic Distribution of CRISPR-Cas Systems in Antibiotic-Resistant Pseudomonas aeruginosa. mBio. 2015;6(6):e01796-15. Epub 2015/11/26. doi: 10.1128/mBio.01796-15. PubMed PMID: 26604259; PubMed Central PMCID: PMCPMC4669384.

47. Emmerson AM, Jones AM. The quinolones: decades of development and use. The Journal of antimicrobial chemotherapy. 2003;51 Suppl 1:13-20. Epub 2003/04/19. doi: 10.1093/jac/dkg208. PubMed PMID: 12702699.

48. Chávez-Jacobo VM, Hernández-Ramírez KC, Silva-Sánchez J, Garza-Ramos U, Barrios-Camacho H, Ortiz-Alvarado R, et al. Prevalence of the crpP gene conferring decreased ciprofloxacin susceptibility in enterobacterial clinical isolates from Mexican hospitals. Journal of Antimicrobial Chemotherapy. 2019;74(5):1253-9. doi:

10.1093/jac/dky562.

49. He J, Baldini RL, Deziel E, Saucier M, Zhang Q, Liberati NT, et al. The broad host range pathogen Pseudomonas aeruginosa strain PA14 carries two pathogenicity islands harboring plant and animal virulence genes. Proceedings of the National Academy of Sciences of the United States of America. 2004;101(8):2530-5. PubMed PMID: 14983043; PubMed Central PMCID: PMCPMC356984.

50. Kung VL, Ozer EA, Hauser AR. The accessory genome of Pseudomonas aeruginosa. Microbiology and molecular biology reviews : MMBR. 2010;74(4):621-41. doi: 10.1128/MMBR.00027-10. PubMed PMID: 21119020; PubMed Central PMCID: PMC3008168.

51. Ramirez-Diaz MI, Diaz-Magana A, Meza-Carmen V, Johnstone L, Cervantes C, Rensing C. Nucleotide sequence of Pseudomonas aeruginosa conjugative plasmid pUM505 containing virulence and heavy-metal resistance genes. Plasmid. 2011;66(1):7-18. Epub 2011/03/23. doi: 10.1016/j.plasmid.2011.03.002. PubMed PMID: 21421005.

52. Subedi D, Kohli GS, Vijay AK, Willcox M, Rice SA. Accessory genome of the multidrug resistant ocular isolate of Pseudomonas aeruginosa PA34. PloS one.

2019;14(4):e0215038. Epub 2019/04/16. doi: 10.1371/journal.pone.0215038. PubMed PMID: 30986237; PubMed Central PMCID: PMCPMC6464166.

53. Fonseca EL, Dos Santos Freitas F, Vieira VV, Vicente AC. New qnr gene cassettes associated with superintegron repeats in Vibrio cholerae O1. Emerging infectious diseases. 2008;14(7):1129-31. Epub 2008/07/05. doi: 10.3201/eid1407.080132. PubMed PMID: 18598639; PubMed Central PMCID: PMCPMC2600354.

54. Belotti PT, Thabet L, Laffargue A, Andre C, Coulange-Mayonnove L, Arpin C, et al. Description of an original integron encompassing blaVIM-2, qnrVC1 and genes encoding bacterial group II intron proteins in Pseudomonas aeruginosa. The Journal of antimicrobial 
chemotherapy. 2015;70(8):2237-40. Epub 2015/05/16. doi: 10.1093/jac/dkv103. PubMed PMID: 25977399.

55. Lin J, Chen DQ, Hong J, Huang H, Xu X. Prevalence of qnrVC Genes in Pseudomonas aeruginosa Clinical Isolates from Guangdong, China. Current microbiology. 2020. Epub 2020/04/05. doi: 10.1007/s00284-020-01974-9. PubMed PMID: 32246181.

56. He P, Moran GR. Structural and mechanistic comparisons of the metal-binding members of the vicinal oxygen chelate (VOC) superfamily. J Inorg Biochem.

2011;105(10):1259-72. Epub 2011/08/09. doi: 10.1016/j.jinorgbio.2011.06.006. PubMed PMID: 21820381.

57. Stokes HW, Hall RM. A novel family of potentially mobile DNA elements encoding site-specific gene-integration functions: integrons. Molecular microbiology. 1989;3(12):1669-83. PubMed PMID: 2560119.

58. Poirel L, Liard A, Rodriguez-Martinez JM, Nordmann P. Vibrionaceae as a possible source of Qnr-like quinolone resistance determinants. The Journal of antimicrobial chemotherapy. 2005;56(6):1118-21. Epub 2005/10/18. doi: 10.1093/jac/dki371. PubMed PMID: 16227349.

59. Keay L, Edwards K, Naduvilath T, Taylor HR, Snibson GR, Forde K, et al. Microbial keratitis predisposing factors and morbidity. Ophthalmology. 2006;113(1):109-16. Epub 2005/12/20. doi: 10.1016/j.ophtha.2005.08.013. PubMed PMID: 16360210.

60. Stapleton F, Keay L, Edwards K, Naduvilath T, Dart JK, Brian G, et al. The incidence of contact lens-related microbial keratitis in Australia. Ophthalmology. 2008;115(10):165562. Epub 2008/06/10. doi: 10.1016/j.ophtha.2008.04.002. PubMed PMID: 18538404. 61. Dötsch A, Klawonn F, Jarek M, Scharfe M, Blöcker H, Häussler S. Evolutionary conservation of essential and highly expressed genes in Pseudomonas aeruginosa. BMC genomics. 2010;11:234. Epub 2010/04/13. doi: 10.1186/1471-2164-11-234. PubMed PMID: 20380691; PubMed Central PMCID: PMCPMC2864246.

62. Jacoby GA, Strahilevitz J, Hooper DC. Plasmid-mediated quinolone resistance. Microbiology spectrum. 2014;2(5):10.1128/microbiolspec.PLAS-0006-2013. Epub 2014/10/24. doi: 10.1128/microbiolspec.PLAS-0006-2013. PubMed PMID: 25584197.

63. Nordmann P, Poirel L. Emergence of plasmid-mediated resistance to quinolones in Enterobacteriaceae. Journal of Antimicrobial Chemotherapy. 2005;56(3):463-9. doi: $10.1093 / \mathrm{jac} / \mathrm{dki} 245$.

64. Tran JH, Jacoby GA. Mechanism of plasmid-mediated quinolone resistance. Proceedings of the National Academy of Sciences. 2002;99(8):5638. doi: 10.1073/pnas.082092899.

65. Fonseca EL, Vicente ACP. Epidemiology of qnrVC alleles and emergence out of the Vibrionaceae family. Journal of medical microbiology. 2013;62(Pt 10):1628-30. Epub 2013/06/27. doi: 10.1099/jmm.0.062661-0. PubMed PMID: 23800600.

66. Subedi D, Vijay AK, Kohli GS, Rice SA, Willcox M. Nucleotide sequence analysis of NPS-1 beta-lactamase and a novel integron (In1427)-carrying transposon in an MDR Pseudomonas aeruginosa keratitis strain. The Journal of antimicrobial chemotherapy. 2018. Epub 2018/03/17. doi: 10.1093/jac/dky073. PubMed PMID: 29547943.

67. Heidary Z, Bandani E, Eftekhary M, Jafari AA. Virulence genes profile of multidrug resistant Pseudomonas aeruginosa isolated from Iranian children with UTIs. Acta medica Iranica. 2016;54(3):201-10. Epub 2016/04/25. PubMed PMID: 27107526.

68. Cho HH, Kwon KC, Kim S, Koo SH. Correlation between virulence genotype and fluoroquinolone resistance in carbapenem-resistant Pseudomonas aeruginosa. Annals of laboratory medicine. 2014;34(4):286-92. Epub 2014/07/02. doi: 10.3343/alm.2014.34.4.286. PubMed PMID: 24982833; PubMed Central PMCID: PMCPMC4071185. 
69. Georgescu M, Gheorghe I, Curutiu C, Lazar V, Bleotu C, Chifiriuc MC. Virulence and resistance features of Pseudomonas aeruginosa strains isolated from chronic leg ulcers. BMC infectious diseases. 2016;16 Suppl 1:92. Epub 2016/05/14. doi: 10.1186/s12879-0161396-3. PubMed PMID: 27169367; PubMed Central PMCID: PMCPMC4890939.

70. Sawa T, Shimizu M, Moriyama K, Wiener-Kronish JP. Association between Pseudomonas aeruginosa type III secretion, antibiotic resistance, and clinical outcome: a review. Critical care (London, England). 2014;18(6):668. Epub 2015/02/13. doi: 10.1186/s13054-014-0668-9. PubMed PMID: 25672496; PubMed Central PMCID: PMCPMC4331484.

71. Tran QT, Nawaz MS, Deck J, Foley S, Nguyen K, Cerniglia CE. Detection of type III secretion system virulence and mutations in gyrA and parC genes among quinolone-resistant strains of Pseudomonas aeruginosa isolated from imported shrimp. Foodborne pathogens and disease. 2011;8(3):451-3. Epub 2010/12/02. doi: 10.1089/fpd.2010.0687. PubMed PMID: 21117986.

72. Agnello M, Finkel SE, Wong-Beringer A. Fitness cost of fluoroquinolone resistance in clinical isolates of Pseudomonas aeruginosa differs by type III secretion genotype. Frontiers in microbiology. 2016;7:1591. Epub 2016/10/21. doi: 10.3389/fmicb.2016.01591. PubMed PMID: 27757111; PubMed Central PMCID: PMCPMC5047889.

73. Garey KW, Vo QP, Larocco MT, Gentry LO, Tam VH. Prevalence of type III secretion protein exoenzymes and antimicrobial susceptibility patterns from bloodstream isolates of patients with Pseudomonas aeruginosa bacteremia. Journal of chemotherapy (Florence, Italy). 2008;20(6):714-20. doi: 10.1179/joc.2008.20.6.714. PubMed PMID: 19129069.

74. Choy MH, Stapleton F, Willcox MD, Zhu H. Comparison of virulence factors in Pseudomonas aeruginosa strains isolated from contact lens- and non-contact lens-related keratitis. Journal of medical microbiology. 2008;57(Pt 12):1539-46. doi:

10.1099/jmm.0.2008/003723-0. PubMed PMID: 19018027.

75. Finck-Barbancon V, Goranson J, Zhu L, Sawa T, Wiener-Kronish JP, Fleiszig SM, et al. ExoU expression by Pseudomonas aeruginosa correlates with acute cytotoxicity and epithelial injury. Molecular microbiology. 1997;25(3):547-57. PubMed PMID: 9302017.

76. Agnello M, Wong-Beringer A. Differentiation in quinolone resistance by virulence genotype in Pseudomonas aeruginosa. PloS one. 2012;7(8):e42973. doi:

10.1371/journal.pone.0042973. PubMed PMID: 22905192; PubMed Central PMCID: PMCPMC3414457.

77. Stewart RM, Wiehlmann L, Ashelford KE, Preston SJ, Frimmersdorf E, Campbell BJ, et al. Genetic characterization indicates that a specific subpopulation of Pseudomonas aeruginosa is associated with keratitis infections. Journal of clinical microbiology. 2011;49(3):993-1003. doi: 10.1128/JCM.02036-10. PubMed PMID: 21227987; PubMed Central PMCID: PMCPMC3067716. 